$\overline{\mathrm{p}}$ Note $\# 394$

UTILITY MONITORING FOR THE ANTIPROTON SOURCE

D. McConne11

$6 / 11 / 84$ 


\section{UTILITY MONITORING FOR THE ANTIPROTON SUURCE}

Dẹnis Mcconnell

11 June 1.484

The purpose of the utility portion of the FIRUS system is to alert humans in the main control room, at Phillips farm, and in building 10 control room when either environmental conditions are unhealthy for antiproton source devices, or electrical or mechanical equipment is malfunctioning. When first envisioned, the FIRUS system consisted of the following equipment:

(1) 2 FIRUS mini-computers (wall mounted, 1 fire, 1 utility)

(2) emergency power supply (also wall mounted)

(3) coax hardline communication cable

(4) Junction boxes

(s) contact points and analog transducers

(6) three-pair 18 gage shielded cable

Each mini can monitor 16 contact points or 15 analog points or a combination of contact and analog points. Each contact point can be more than one physical point if the points are wired in series. An alarm then indicates any one of a group of points has opened.

The following devices/quantities are proposed to be monitored by the utility portion of the FIRUS system:

(1) sump pumps

(2) LCW (Low Conductivity Water)

(j) auxiliary generator

(4) service building temperatures

(5) stub room/tunnel temperature

(b) stub room/tunnel humidity

After the number of quantities to be monitored (see table I) was determined. it was found that two or three minis would be required. or a FIRUS crate could be used. A FIRUS crate is an "old beam transfer crate" with 25 slots which hold cards to either monitor 16 contact points or 15 analog points. The space requirement for the crate systen is about half a relay rack. The emergency power supply could remain wall mounted. or it could be rack mounted with the firus crate. Conversations with Al Franck and Rich Mahler concerning availability, expandability, cabling, and cost indicate that the FIRUS crate is the preperable option for the antiproton source.

lwo contact sets per sump pump would be used. The first opens when a controliing float reaches a high water position, and the second opens upon loss of 120 VAC power. to the pump. 
Ine LCW cooling system for the rings enrlosure will be derived from new equipment in the central utility builoing (cub). One transducer for water pressure and one transducer for water temperature will located just downstream of the looogpm.150psi pump in CUB. The LCW cooling system for the antiproton target hall and pretarget enclosure wll be extended from the main ring LCW system at service building F-23. Since the main ring LCW system is already monitored by FIRUS, no additional monitoring is necessary, as is true of the hot water (HTW) and chilled water (CHW) systems used for heating and airconditioning.

The auxiliary power generator (to be located outside service building so) has a panel (to be located inside service building 50) with 8 monitors of contacts. A FIRUS contact will be wired such that if any one of these $B$ monitors trips, the FIRUS contact will open. indicating trouble with the auxiliary power system.

Service building temperatures are proposed to be monitored with either one to three distributed contacts that open upon a high temperature limit and one contact that opens upor a low temperature limit or two distributed analog temperature señörs with fIRUS software set 1 imits. The service buildings are heated and airconditioned, so temperature monitoring provides a check on the correct operation of the air handiing units. The high temperature limit will insure a healthy environment for the electronic equipment, and the low temperature limit will protect water pipes from freezing in winter.

An analog temperature sensor with fIRUS software set limits is proposed for the stub rooms. Human access to the antiproton rings enclosure will be prohibited if a beam is present. Remote monitoring of environmental temperature allows an.operator to comfortably assess any long term danger to electronic equipment and decide if and when an access should be preformed to investigate a high temperature indication. Also, during bakeout of the accumulator, access to the rings enclosure will he possible, but not comfortable. The high temperature limit for electronics is higher when the electronics are not operating, and the flexibility of a analog temperature sensor would be very useful

The rings enclosure is heated and indirectly airconditioned by service building forced air ventilation. The possibility of electrical equipment damage due to condensation exists in the surniner when warm. humid air could be cooled in the nearly constant temperature, below ground rings enclosure. An analog humidity sensor, with a FIRUS software set linit is proposed in sselected stubrooms to provide a check on the ventilation system.

Hecause of the linited access to the rings enclosure, the selection of temperature and humidity transducers to be located there should emphasize high reliability and no periodic maintenance or calibration

Following is a list of monitor points (table I) and a list of sensor hardware (table II). 


\section{FIRUS}

\section{MAC ROOM}

$\underline{1}$

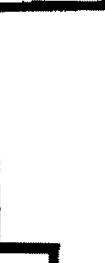

|ाIा\| $\|ा\| ा \|$

-

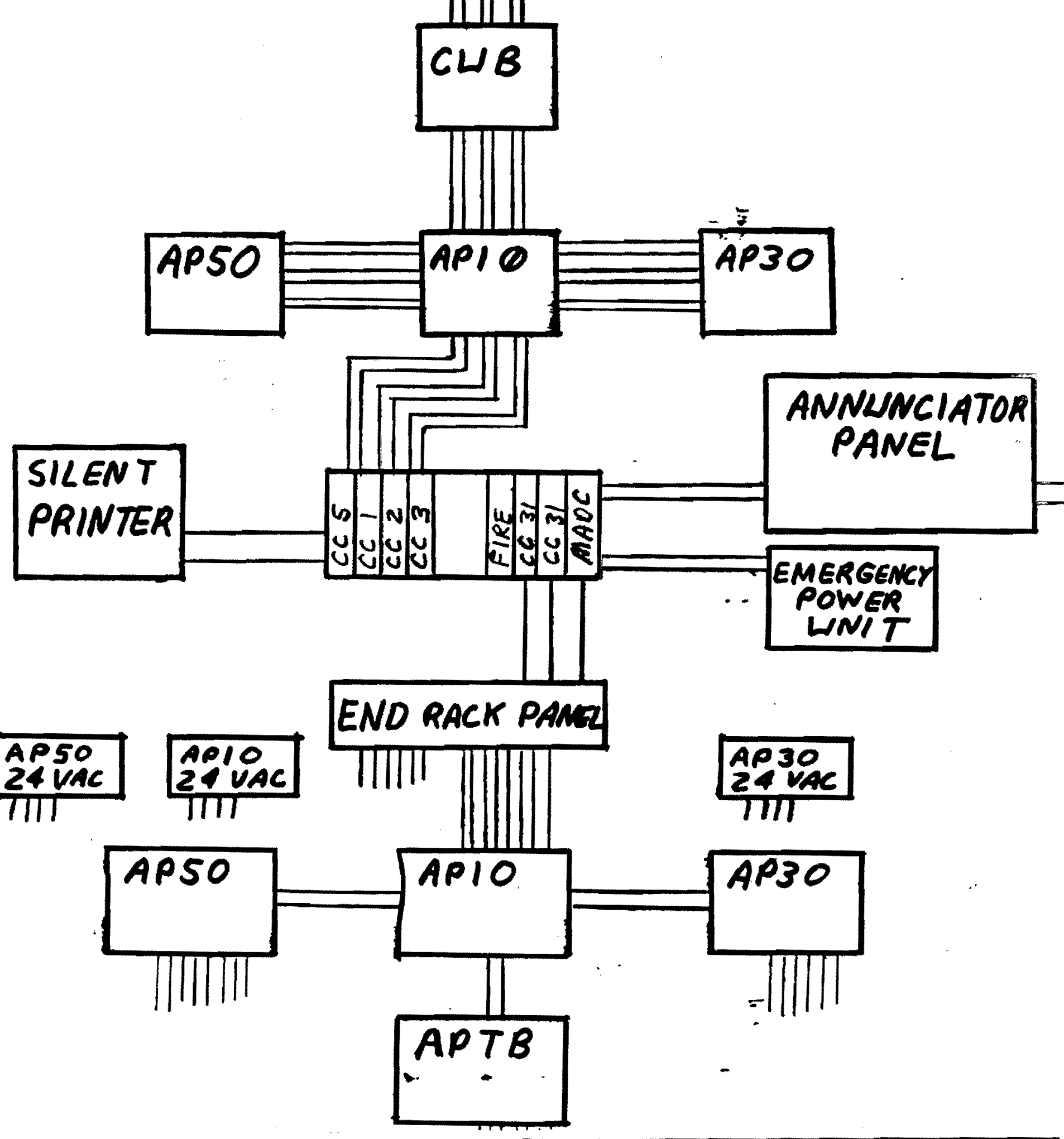


TABLE I

ANTIPROTON UTILITY MONITORING PONS TYPE, $C=R E L A Y$ CONTACT, $A=$ ANALOG

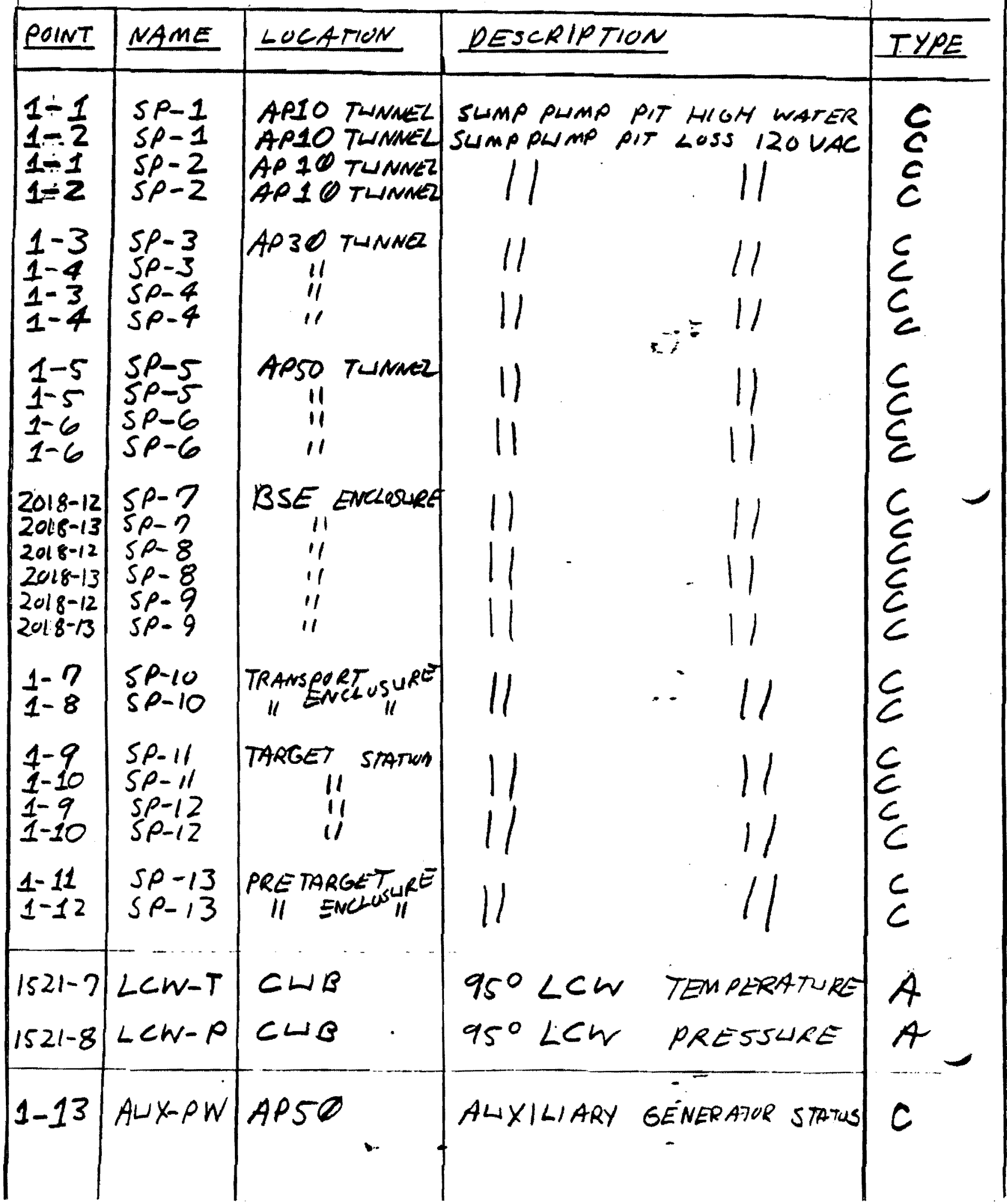




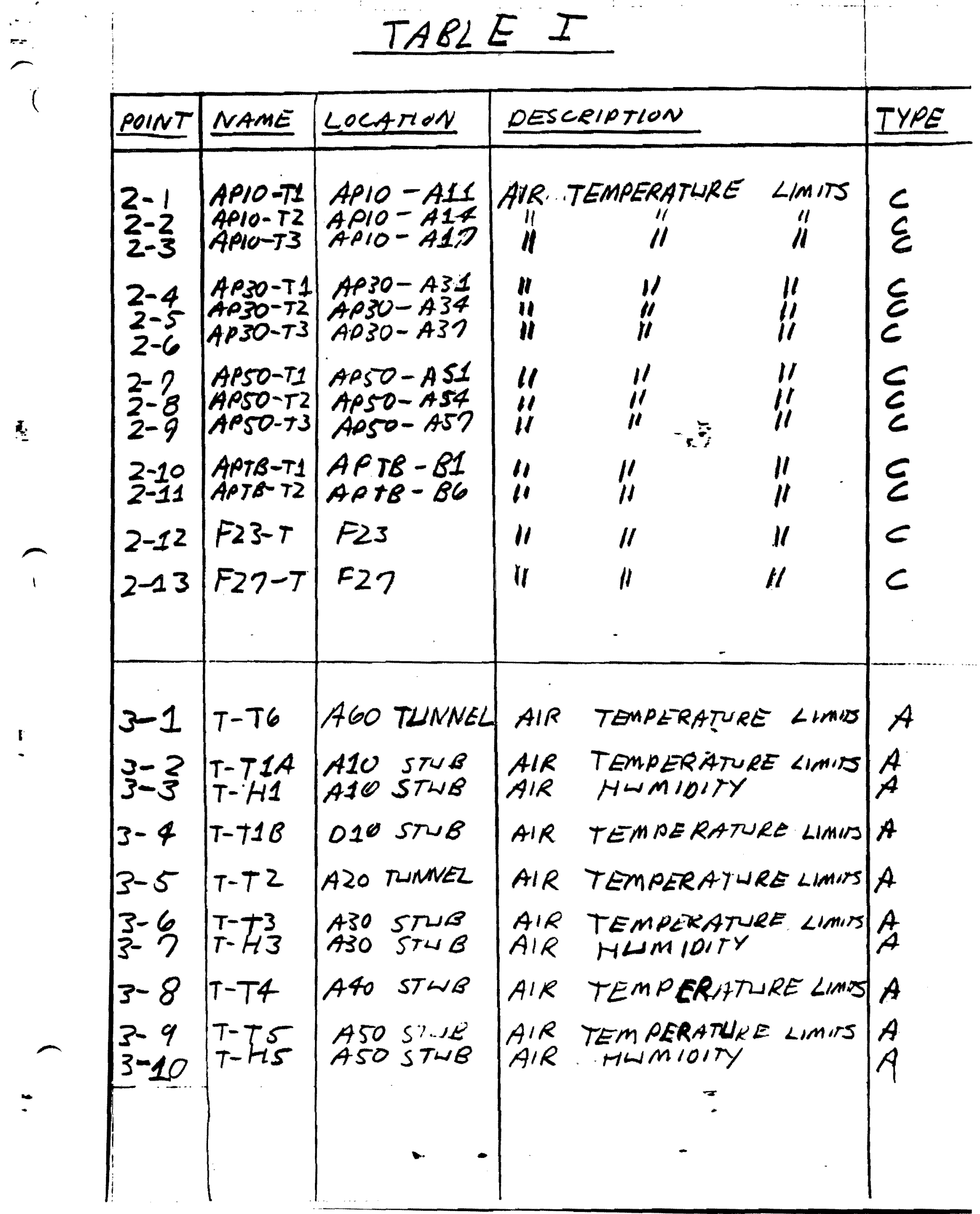


TABLE II FIRWS SENSOR HAROWARE

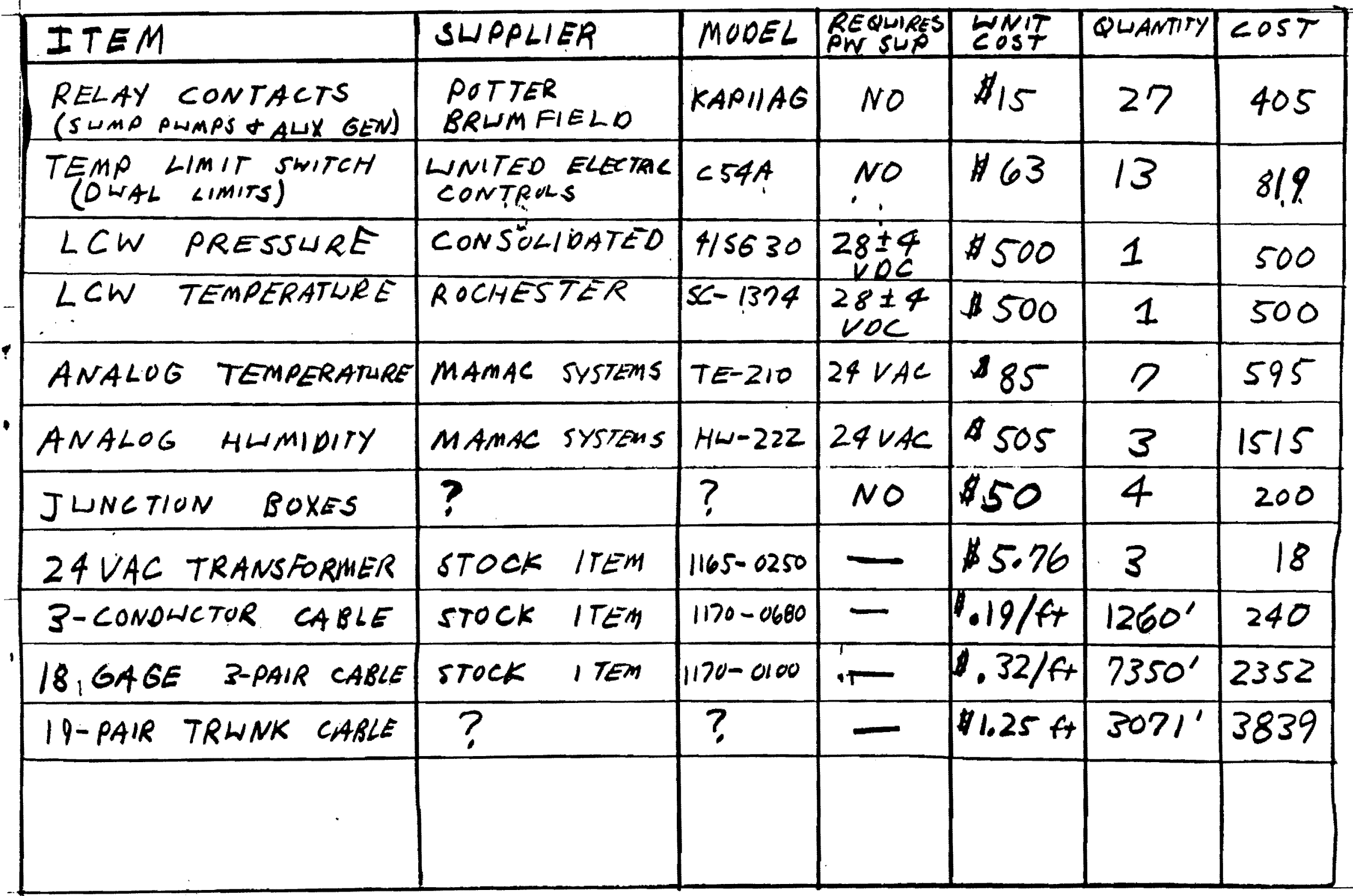

TOTAL \$10,983 


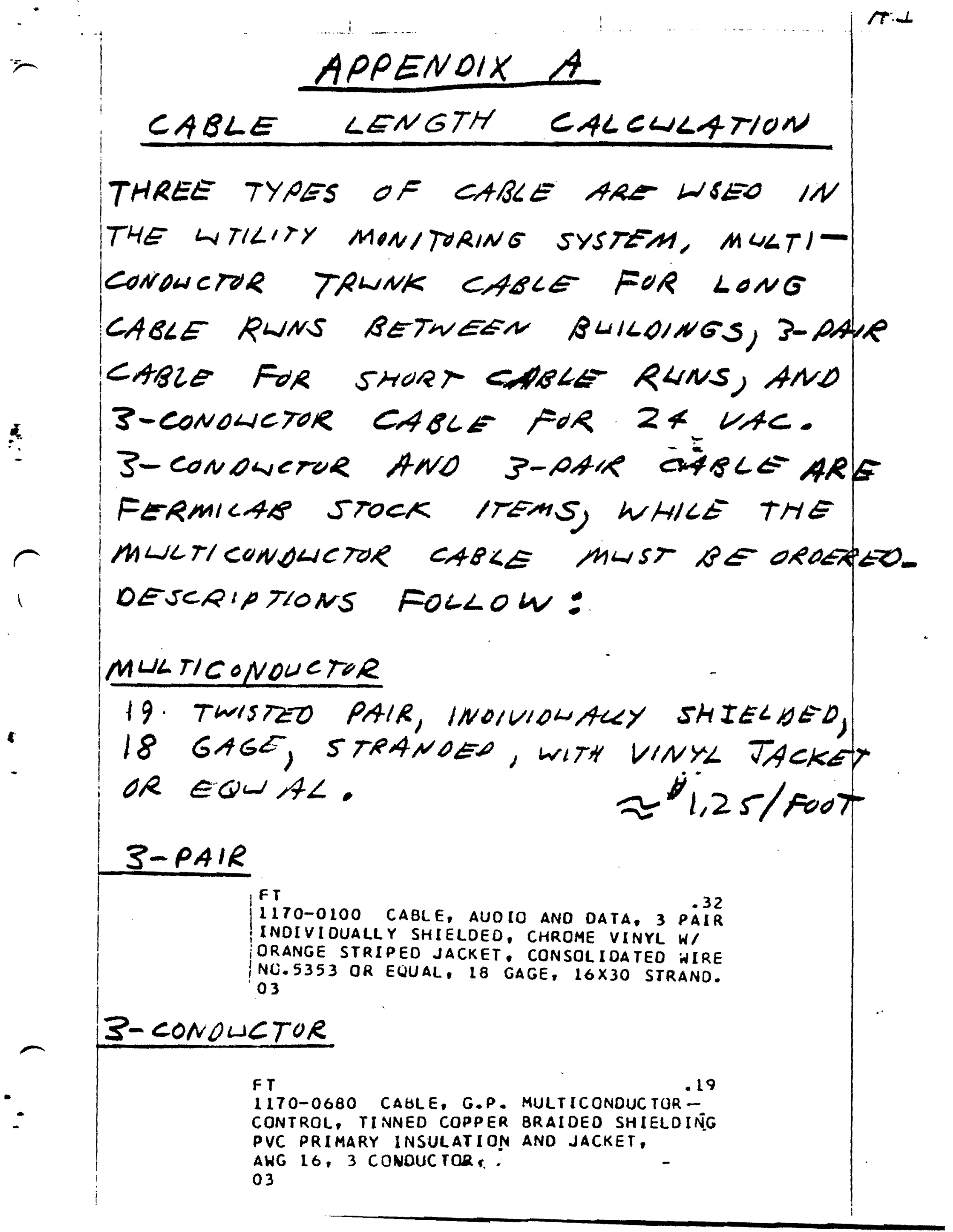




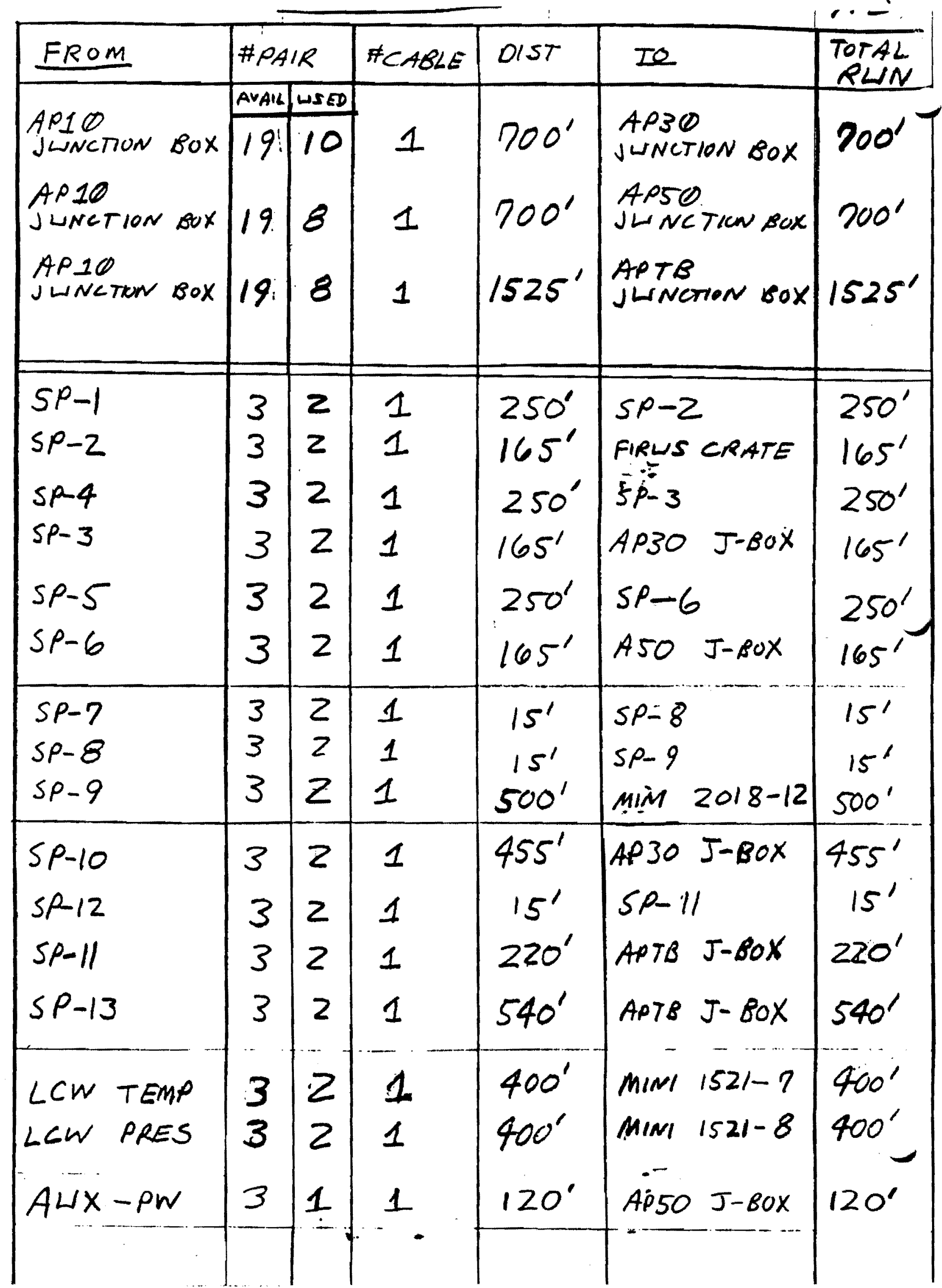




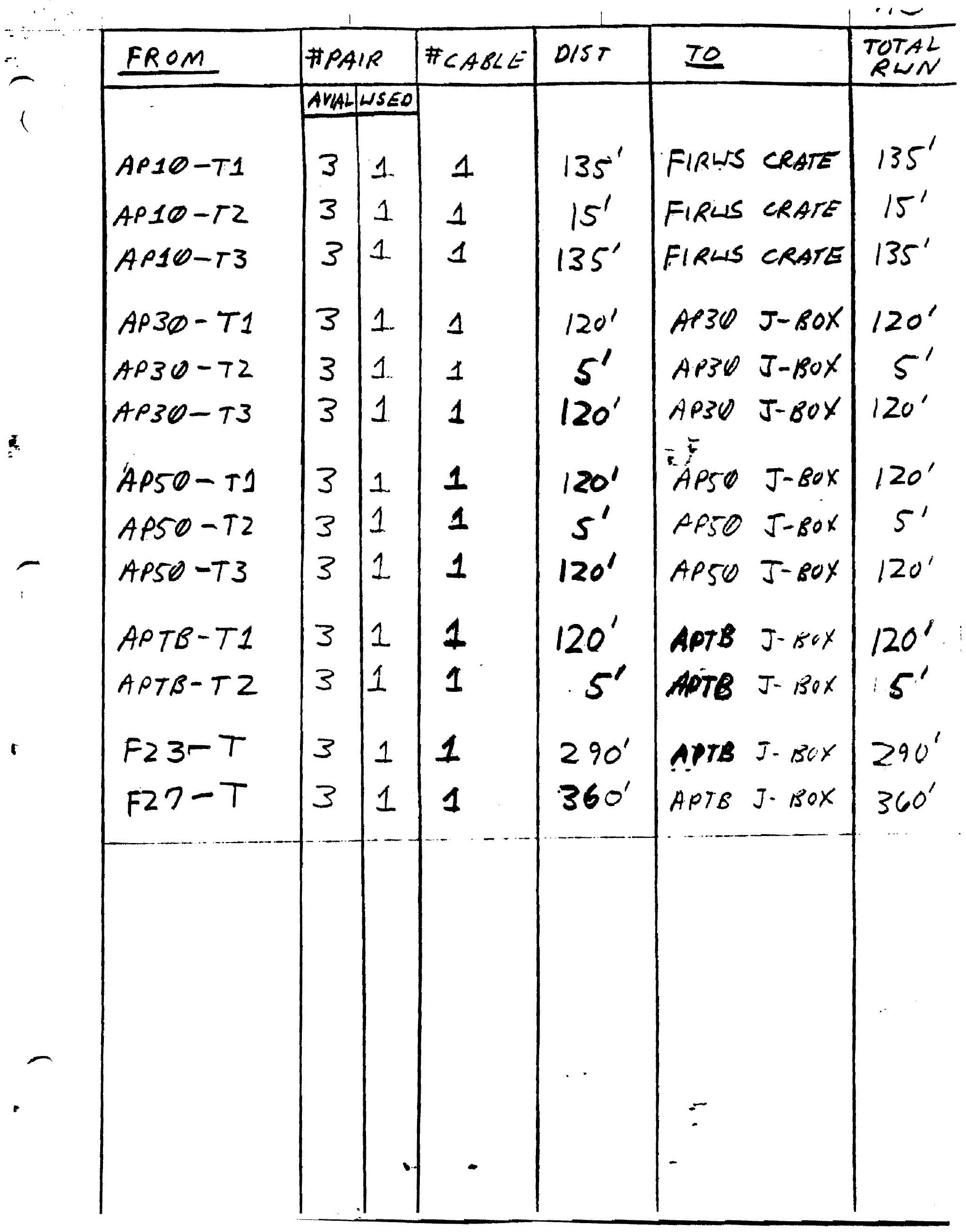




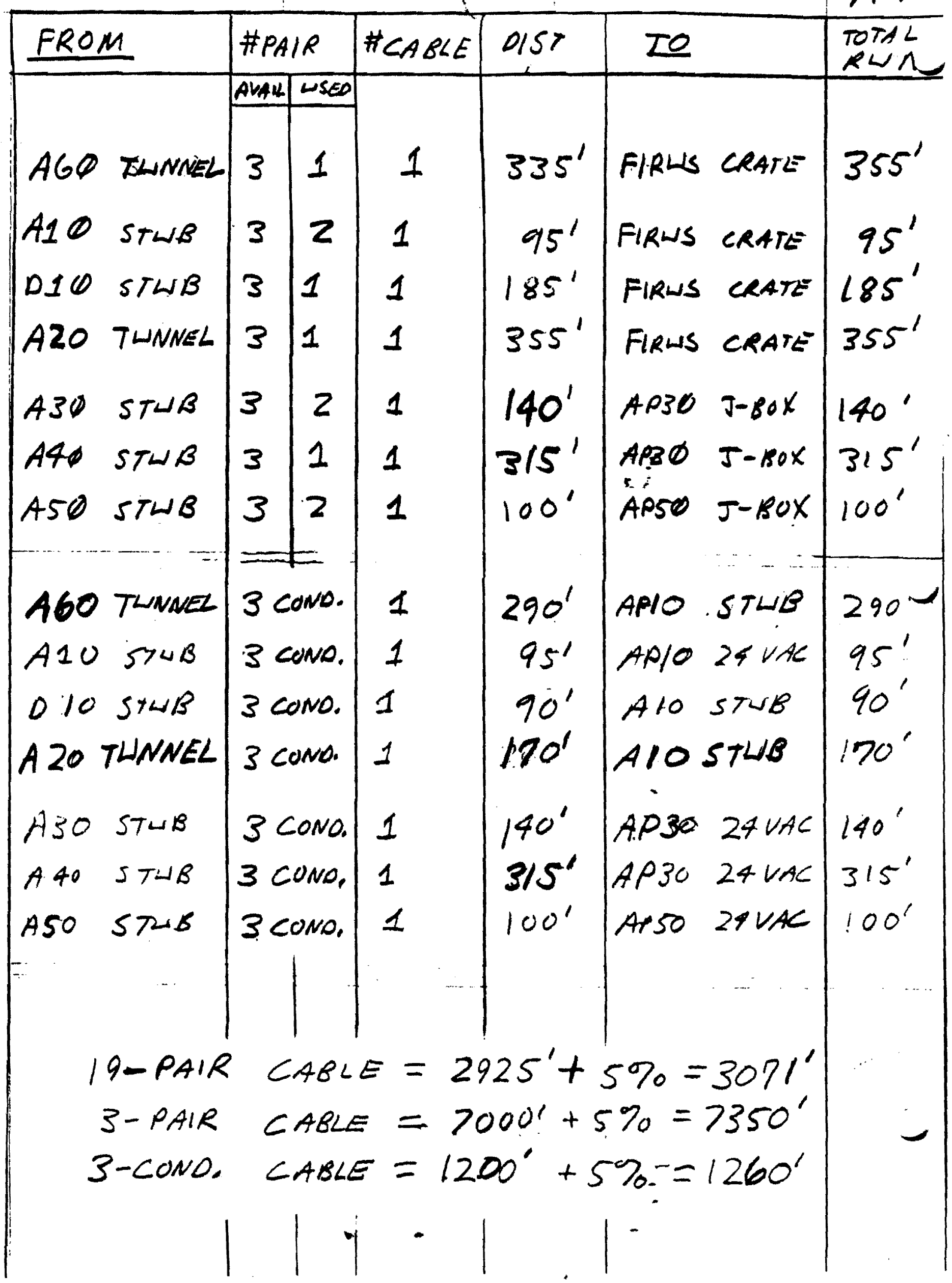

